\title{
RAGAM DAN ORIENTASI MEMORI ATAS SOEHARTO DALAM BERITA KOMPAS.COM
}

\author{
Muhammad Aswan Zanynu \\ Jurusan Ilmu Komunikasi, Univeristas Haluoleo, Kendari. \\ e-mail:azanynu@gmail.com
}

\begin{abstract}
Soeharto was a political leader who became a determinant factor in Indonesia for three decades. On January 2016, Kompas.com published the special report to remembering Soeharto that passed away eight years before. This research aims 1) to identify items of memory about him that are considered still actual nowadays, 2) to find orientation of memory about Soeharto, it's just a kind of reconstruction the past -we call it "retrospective memory", or the news content were directed to do something in the future -we call it "prospective memory". To fulfill these purposes, 47 news samples are researched by using framing analysis. The news had published on January 2016 and January 2008 (as a comparation) in Kompas.com site. The study shows that 1) informative memory about Soeharto is dominant -without positive or negative tone, and 2) most of all news tends to be constructed as retrospective memory.
\end{abstract}

Keywords : Soeharto, retrospective memory, prospective memory, online news

\begin{abstract}
ABSTRAK
Soeharto adalah pemimpin politik yang menjadi faktor determinan bagi arah Indonesia selama tiga dekade. Pada bulan Januari 2016, Kompas.com menurunkan liputan khusus mengenang sewindu wafatnya Soeharto. Penelitian ini bermaksud untuk 1) mengidentifikasi ragam memori yang ditekankan kembali dan dianggap masih aktual tentang Soeharto, 2) menemukan orientasi memori, merekonstruksi kembali apa yang telah terjadi di masa lalu (retrospektif) atau justru diarahkan untuk tujuan-tujuan masa depan (prospektif). Untuk itu dilakukan analisis framing atas 47 berita yang dipublikasikan melalui Kompas.com pada Januari 2016 dan Januari 2008 (sebagai pembanding). Hasil penelitian menunjukkan bahwa: 1) memori yang ditonjolkan sangat bersifat informatif tanpa penekanan pada aspek positif atau negatif atas Soeharto, dan 2) hampir semua pemberitaan terkait sewindu wafatnya Soeharto sangat bersifat retrospektif.
\end{abstract}

Kata kunci : Soeharto, memori retrospektif, memori prospektif, berita online

\section{PENDAHULUAN}

Mungkin sangat terbatas orangorang yang mengenal Soeharto (19212008) lebih dari sebagai mantan
Presiden Repubulik Indonesia. Tiga dekade menjadi kepala negara tentu banyak hal yang dilakukannya dan 
berdampak pada arah perjalanan Indonesia sebagai bangsa. Sejarah mencatat sisi cemerlang juga kelamnya. Banyak buku yang memuat sejarah hidup dan apa saja yang ia lakukan, termasuk peran atau keterlibatannya dalam berbagai peristiwa penting.

Narasi yang muncul di awal khususnya pada saat ia masih memerintah, lebih memposisikan dirinya sebagai pahlawan. Narasi sejarah yang berbeda dengan versi pemerintah tidak dapat muncul ke publik. Mengutip laporan Human Right Watch tahun 1998, selama tiga dekade Orde Baru, lebih dari 2.000 buku dinyatakan terlarang. Selain itu, pemerintah juga melakukan sensor yang sangat ketat atas isi setiap publikasi termasuk melarang seminar tentang tentang sejarah jika hal tersebut dirasa perlu. Dalam satu dekade terakhir, pemerintahan Orde Baru sedikitnya melarang 12 diskusi umum yang bertema sejarah Indonesia 1957-1958 dan 1965-1966 (van Klinken, 2005, p.235).

Setelah ia tidak berkuasa lagi, narasi yang berbeda justru yang banyak bermunculan sebagai bentuk koreksi atas narasi yang lebih dulu ada. Pada tahun 2006 - dua tahun sebelum Soeharto wafat- George Junus Aditjondro mempublikasikan buku yang membeberkan bukti-bukti kekayaan
Soeharto, keluarga, dan kroninya dari hasil korupsi. Asvi Warman Adam (2009) menulis tentang manipulasi sejarah yang terjadi di masa Soeharto. Setahun setelahnya, McGlynn (2007) juga menjadi editor atas sejumlah tulisan yang berupaya untuk merekonstruksi kembali beberapa isu penting semasa Soeharto berkuasa. Tiga penulis tadi hanya mewakili sebagian dari narasi yang bertujuan mengkritik Soeharto. Tetapi buku-buku yang membelanya juga tidak kalah jumlahnya. Para penyokongnya ingin meneguhkan kembali posisi Soeharto sebagai seorang pahlawan yang layak untuk dihormati.

Tanggal 27 Januari 2008, Soeharto wafat. Setelah delapan tahun berlalu, sejumlah media online masih mewartakan perihal kematian Soeharto. Masa lalu dikemas kembali menjadi sebuah peristiwa yang aktual untuk dikenang. Satu yang secara khusus menurunkan liputan tentang isu tersebut adalah Kompas.com. Menarik dan penting untuk kemudian mengkaji memori yang disajikan media atas Soeharto. Hal apa saja yang dilakukan Soeharto selama lebih dari tiga dekade dapat menjadi pelajaran bagi bangsa Indonesia. Jika ada kebaikan yang harus ditiru, bukanlah hal yang memalukan jika melanjutkan kembali dan memodifikasi keberhasilan tersebut 
dalam konteks terkini. Jika ada keburukan yang harus dihindari, adalah sesuatu yang tepat jika setiap generasi mengatahui kesalahan seperti apa yang jangan terulang lagi dan tahu cara untuk mencegahnya.

\section{KERANGKA PEMIKIRAN}

Segala sesuatu adalah sejarah, demikian klaim Simpson (2011: 255). Apa yang ia kemukakan ini berangkat dari asumsi bahwa sejarah tersusun atas memori dan makna. Baginya keserbahadiran sejarah (history omnia) merupakan sebuah keniscayaan karena setiap individu, kelompok, institusi sosial, hingga peradaban merupakan endapan memori dan makna seiring perjalanan waktu. Dia sengaja menggunakan kata "everything” bukan "all" untuk menghindari bias pemaknaan. Kata "all" dapat menggiring pada perspektif seolah seluruh yang ada di dunia ini adalah sejarah. Oleh karena itu ia menggunakan kata "everything" untuk memberi penekanan bahwa setiap entitas dalam segala tingkatannya memiliki sejarahnya masing-masing.

Memori yang dimaksud Simpson tidak berpretensi mengabaikan fakta sejarah. Penggunaan kata "memori" untuk memberi penekanan bahwa fakta sejarah dibangun dari kumpulan memori atas suatu peristiwa atau tokoh. Memori bukanlah peristiwa atau tokoh itu sendiri. Memang betul bahwa sejarah dapat dilihat sebagai sebagai peristiwa yang dialami (histoire-realite) dan sejarah sebagaimana diceritakan (histoire-recit) seperti yang dikemukakan Adam (2009). Tetapi lagilagi, segala hal yang dialami oleh seorang saksi mata atau bahkan pelaku dalam sebuah peristiwa pun pada akhirnya akan melibatkan memori. Mereka harus mengingat kembali apa yang telah mereka alami. Jika histoirerealite melibatkan memori dari sumber primer, maka histoire-recit lebih mengandalkan memori dari sumber sekunder. Sejarah dan memori kemudian menjadi dua konsep yang berkaitan dan disajikan oleh media massa.

Dengan publikasi berita yang sifatnya terus menerus, media mengarahkan publik kepada hal yang 'harus' diingat, mengabaikan apa yang tidak relevan untuk diingat dalam konteks terkini. Meski media massa ingin berperan sebagai penyedia arena bagi memori kolektif, dengan fungsi gatekeeping yang mereka lakukan, pada akhirnya isi media lebih merupakan cerminan hasil seleksi atas sejumlah memori yang ada. Kontestasi yang terjadi di ranah media tidak terlapas dari 
campur tangan dan cara media membaca kembali masa lalu.

Tenenboim-Weinblatt (2011) menawarkan ide untuk tidak terfokus pada kajian memori yang berorientasi pada masa lalu saja (restrospektif), tetapi juga mengajukan ide agar jurnalis lebih berperan agen memori prospektif yang menyadarkan publik akan apa yang seharusnya dilakukan dengan merujuk pada masa lalu.

Exploring the
role of
journalism as an
agent of
prospective
memory, rather
than only as an
agent of
retrospective
memory, can
add an
important
dimension to
our
understanding
of how
journalists work
out and
negotiate the
complex
relationship
between past,
present, and

future in the

coverage of

current events

(Tenenboim-

Weinblatt, 2011,

p. 214).

Dari sini akan terungkap jarak waktu memori ke belakang (retrospective memory) dan ke depan (prospective memory) yang tersaji dalam berita. Rentang memori akan mengidentifikasi pilihan-pilihan memori yang dihadirkan kembali (recall). Singkatnya, memori diharapkan dapat menjadi rujukan atas tindak-tindakan kolektif saat ini untuk orientasinya ke masa yang akan datang.

Apa yang ditawarkan oleh Tenenboim-Weinblatt (2011) serupa dengan yang dikemukakan Fine (2005: 117) dengan mengutip Schwartz yang menganalogikan cara memperlakukan masa lalu sebagai cermin atau sebagai lampu sorot. Jika memperlakukan masa lalu sebagai cermin, kita akan melihat sebentuk model dari masyarakat (model of society). Tetapi jika menggunakan masa lalu sebagai sebuah lampu sorot, kita akan menemukan model masyarakat yang kita ingin capai (model for society). Metafora ini adalah bentuk penggambaran bagaimana memori kolektif dapat merepresentasikan 
kepercayaan kita atas keadaan masyarakat kita saat ini, juga dapat merepresentasikan bagaimana masyarakat kita seharusnya keadaan tersebut di masa yang akan datang.

\section{TUJUAN PENELITIAN}

Dua hal yang menjadi fokus penelitian ini. Pertama, berkaitan dengan ragam memori dari Soeharto yang ditekankan kembali dan dianggap masih aktual hingga sewindu sepeninggalnya. Secara umum ragam memori tersebut dikelompokkan ke dalam tiga kategori: positif, informatif, dan negatif. Kedua, bentuk kemasan atas memori tersebut diarahkan untuk sekedar merekonstruksi kembali apa yang telah terjadi di masa lalu (retrospektif) atau justru diarahkan untuk tujuan-tujuan masa depan (prospektif).

\section{METODE PENELITIAN}

Untuk menyelisik ragam memori dan arah orientasinya, penelian ini memilih berita yang dimuat dalam liputan khusus Kompas.com. Ada tiga alasan sehingga situs ini dipilih. Pertama, dibandingkan dengan situs berita yang lain, Kompas.com secara khusus membuat liputan tentang topik yang diteliti. Kedua, Di tahun 2016, situs ini juga masuk dalam kategori lima besar situs berita yang terpopuler di Indonesia menurut Alexa.com. Ketiga, Kompas merupakan media berita yang tertua di Indonesia (terbit sejak 28 Juni 1965). Database informasi yang mereka miliki memberi keleluasaan bagi Kompas.com untuk mengkonstruksi memori tentang Soeharto.

Terdapat total 47 berita yang digunakan sebagai obyek penelitian. Keseluruhan dibagi menjadi dua kelompok. Kelompok pertama (tahun 2016), terdiri dari 14 berita yang dipublikasikan dari kurun waktu 26 sampai 28 Januari 2016 dalam liputan khusus berita sewindu wafatnya Soeharto. Kelompok kedua (tahun 2008), terdiri dari 33 berita yang terpublikasikan di Kompas.com dalam kurun waktu 27 sampai 31 Januari 2008. Kelompok berita yang kedua ini digunakan untuk menjadi pembanding intertekstualitas dalam mengidentifikasi ragam dan pergerakan orientasi berita terkait wafatnya Soeharto setelah berselang sewindu (delapan tahun).

Penelitian ini menggunakan metode analisis framing. Analisis framing memungkinkan kita untuk mengklasifikasi, mengatur, dan menginterpretasikan pengalaman hidup kita ke ranah yang mudah untuk dipahami. Bagan interpretasi yang diberi label dengan menggunakan frame (bingkai) tertentu memungkinkan 
individu untuk menemukan, mempersepsi, mengidentifikasi, dan memberi tanda pada setiap kejadian atau informasi (Goffman, 1974, p. 21).

Eriyanto menitikberatkan framing pada dua aspek yaitu seleksi dan penekanan isu. Dari sejumlah definisi yang ia sarikan terkait metode ini, penelitian ini lebih dekat pada definisi yang dikemukakan oleh Todd Gitlin yang melihat framing sebagai "strategi bagaimana realitas/dunia dibentuk dan disederhanakan sedemikian rupa untuk ditampilkan kepada khalayak pembaca. Peristiwa-peristiwa ditampilkan dalam pemberitaan agar tampak menonjol dan menarik perhatian khalayak pembaca. Itu dilakukan dengan seleksi, pengulangan, penekanan, dan presentasi aspek tertentu dari realitas" (Eriyanto, 2011, p. 78).

Adapun untuk kerangka analisisnya, peneliti menggunakan medel yang dikemukakan Pan dan Kosicki. Dengan empat unit pengamatan. Pertama, sintaksis yang meliputi headline, lead, latar informasi, kutipan sumber, penyataan, dan penutup. Kedua, skrip yang terdiri dari unsur what, who, where, when, why (5W) dan how $(1 \mathrm{H})$. Ketiga, tematik berupa unit paragraf, proposisi, kalimat, hubungan antarkalimat. Keempat, retoris berupa kata, idiom, gambar/foto, atau grafik (Eriyanto, 2011, p. 295).

\section{HASIL DAN PEMBAHASAN}

Dari 14 berita yang dianalsis, diksi yang digunakan dalam judul berita lebih condong bermuatan nilai positif, setidaknya informatif. Tidak ada redaksi judul yang secara langsung dibingkai dalam makna yang berkonotasi negatif. Sebagai ilustrasi, "Warisan Soeharto" (27/1/2016) dan "Soeharto, Sosok Presiden yang Penuh Misteri” (27/1/2016) adalah dua berita judul yang cenderung bersifat netral. Tetapi saat menyelisik isinya, akan ditemukan sejumlah memori negatif atas Soeharto.

Berikut ini ragam memori yang hadir dalam pemberitaaan yang intisarinya disajikan dalam bentuk matriks. 


\begin{tabular}{|c|c|}
\hline & $\begin{array}{c}\text { Matriks 1 } \\
\text { Ragam Memori dalam Pemberitaan } \\
\text { Sewindu Wafatnya Soeharto di Kompas.com }\end{array}$ \\
\hline MEMORI & 2016 \\
\hline Positif & $\begin{array}{l}\text { Soeharto memiliki visi pembangunan yang cemerlang, di masanya pengangguran rendah, } \\
\text { harga barang murah, swasembada pangan, stabilitas politik dan hidupnya rasa aman } \\
\text { (28/1/2016). Fadli Zon menilai Soeharto memiliki jasa yang lebih besar daripada apa } \\
\text { yang dikritikkan atasnya (27/1/2016). Dia pemimpin yang memiliki kontrol diri dan } \\
\text { mental yang hebat. Meski demikian, dia memiliki sisi lembut sebagai manusia yang } \\
\text { terlihat terkhusus saat Ibu Tien meninggal (28/1/2016). Soeharto muda adalah tipe lelaki } \\
\text { yang pemalu, yang saat menikah setia dan sayang pada keluarga (28/1/2016). Di mata } \\
\text { Agung Laksono, Soeharto adalah negarawan yang teliti, sederhana tetapi berwibawa } \\
\text { (27/1/2016). Tri Sutrisno mengenang Soeharto sebagai sosok yang gemar blusukan tanpa } \\
\text { diketahui media, bahkan Panglima ABRI. Tidak protes atau marah saat ajudannya } \\
\text { mengambil rute jalan yang salah. Tidak menyusahkan warga karena membawa sendiri } \\
\text { logistik dari Jakarta (27/1/2016). }\end{array}$ \\
\hline Informatif & $\begin{array}{l}\text { Kronologi wafatnya Soeharto sewindu lalu (27/1/2016). Kisah Kapolsek Kabayoran Baru } \\
\text { yang pertama kali mengabarkan tentang wafatnya Soeharto (27/1/2016). Di Astana } \\
\text { Giribangun tempat peristirahatan terakhir Soeharto (27/1/2016) dan deskripsi } \\
\text { kompleksnya }(27 / 1 / 2016) \text {. Biografi singkat Soeharto, sejak lahir di Kemusuk sampai } \\
\text { wafatnya (27/1/2016). Presiden Susilo Bambang Yudhoyono yang mengumumkan } \\
\text { berkabung nasional dengan mengibarkan bendera setengah tiang selama tujuh hari } \\
(26 / 1 / 2016) \text {. }\end{array}$ \\
\hline Negatif & $\begin{array}{l}\text { Soeharto seorang ambisius. Melakukan sejumlah rekayasa politik untuk meraih } \\
\text { kekuasaan dan melanggengkannya seperti: Pemilu yang tidak adil, dikungkungnya } \\
\text { kebebasan pers, fusi partai politik, dan memberi porsi yang besar kepada militer dalam } \\
\text { politik (28/1/2016). Ia figur pemimpin yang represif, diktator, tidak memberi ruang pada } \\
\text { kebebasan sipil, juga melakukan pelanggaran HAM (27/1/2016). Soeharto serupa dengan } \\
\text { Soekarno, tulis Jakob Oetama. Mereka memerintah dalam waktu yang lama dan sama- } \\
\text { sama jatuh dari kekuasaannya. Soeharto sosok yang cerdas, sayangnya kekuasaaannya } \\
\text { tumbuh dengan gaya feodal. Dia kehilangan kontrol atas korupsi, kolusi, dan nepotisme } \\
(27 / 1 / 2016) \text {. }\end{array}$ \\
\hline
\end{tabular}

Sumber: Data Primer (2017)

Ada tiga berita yang di dalamnya memuat memori negatif atas Soeharto: "Soeharto, Sosok Presiden yang Penuh Misteri” (27/1/2016), "Warisan Soeharto" (27/1/2016), dan "Soeharto dalam Memori: Runtuhnya Ambisi Kekuasaan Bapak Pembangunan" (28/1/2016). Ketiga berita ini pada dasarnya tidak hanya memuat memori negatif tetapi juga positif. Hal yang membedakannya terdapat dalam aspek tematik berupa unit paragraf, proposisi, kalimat, hubungan antarkalimat.

Unit tematik berita bertajuk "Soeharto, Sosok Presiden yang Penuh Misteri” (27/1/2016), struktur beritanya berakhir dengan penekanan pada memori negatif seperti pelanggar HAM dan diktator. Sementara berita "Warisan Soeharto" (27/1/2016), dan "Soeharto dalam Memori: Runtuhnya Ambisi Kekuasaan Bapak Pembangunan” (28/1/2016) proposisi dan hubungan 
antarkalimatnya berakhir dengan penekanan pada sisi positif Soeharto berupa memori atas rasa aman, rendahnya inflasi, swasembada pangan, dan stabilitas politik.

Secara keseluruhan, framing memori dalam peringatan sewindu wafatnya Soeharto, lebih banyak yang menekankan pada aspek informatif dengan menyisakan catatan-catatan

Matriks 2

\section{-poin Memori dalam Pemberitaan Wafatnya Soeharto} Kompas.com 2008

\begin{tabular}{|c|c|}
\hline \\
\hline NEGATIF & POSITIF \\
\hline $\begin{array}{l}\text { - Pertanggungjawaban atas G30S/PKI, Pembunuhan } \\
\text { Misterius tahun 1980an, Peristiwa Tanjung Priok, dan } \\
\text { invasi Timor-Timur, dan kepada (eks) tahanan politik. }\end{array}$ & $\begin{array}{l}\text { - usulan gelar pahlawan } \\
\text { - kisah heroik menumpas G30S }\end{array}$ \\
\hline $\begin{array}{l}\text { - penyelesain pelanggaran hukum terkait TAP MPR No } \\
\text { XI/1998 ttg Korupsi, Kolusi, dan Nepotisme } \\
\text { - koruptor }\end{array}$ & - kerja sosial yayasan-yayasan Soeharto \\
\hline $\begin{array}{l}\text { - melakukan kontrol atas kampus (membungkam } \\
\text { kebebasan akademik) } \\
\text { - pendiam (tertutup) }\end{array}$ & $\begin{array}{l}\text { - menganut kearifan Jawa, arif-bijaksana, } \\
\text { toleran atas agama lain, berani ambil } \\
\text { risiko, konsekuen, tegas, ulet, murah } \\
\text { senyum }\end{array}$ \\
\hline - krisis ekonomi imbas kebijakan Soeharto & $\begin{array}{l}\text { - kebijakan ekonomi dan pertanian yang } \\
\text { konsisten, bawa Indonesia dari negara } \\
\text { miskin jadi negara berkembang } \\
\text { - sukses mengatasi hiperinflasi } 1965\end{array}$ \\
\hline & - penghargaan-penghargaan Soeharto \\
\hline
\end{tabular}

Sumber: Data Primer (2017)

Begitu banyaknya poin yang tereduksi selama kurun waktu delapan tahun menunjukkan bahwa poin-poin tersebut, seiring waktu, tidak lagi menjadi titik tekan memori tentang Soeharto seperti mengevaluasi pelaksanakan amanat TAP MPR No XI/1998. Dari Matriks 2 juga terlihat bahwa ada beberapa hal yang mengalami simplifikasi. Mengenang sewindu tentang sisi kelam Soeharto selama memerintah. Meski demikian, penekanan sisi positif masih lebih menonjol daripada memori negatif atasnya. Sebagai pembanding, berikut matriks poin-poin memori yang ditemukan dalam penelusuran intertekstualitas atas berita Kompas.com yang terpublikasi pada Januari 2008.

- penghargaan-penghargaan Soeharto

\section{Poin}


sinyalemen

Tenenboim-Weinblatt

(2011) terbukti dalam penelitian ini. Dari

keseluruhan berita di tahun 2016, hanya

ada satu berita yang menunjukkan bentuk memori prospektif. Itu pun disampaikan secara implisit seperti yang tampak dalam matrisk berikut.

Matriks 3.

Orientasi Memori dalam Pemberitaan

Sewindu Wafatnya Soeharto di Kompas.com

\begin{tabular}{|l|l|}
\hline ORIENTASI & $\mathbf{2 0 1 6}$ \\
\hline Retrospektif & $\begin{array}{l}\text { Hampir semua berita yang ditampikan berisi memori atas Soeharto dan peristiwa } \\
\text { yang melingkupinya di masa lalu. Untuk sisi kepribadiannya, kedua sisi dihadirkan: } \\
\text { positif maupun negatif. Termasuk penilaian normatif atas hal-hal yang ia lakukan } \\
\text { saat menjadi Presiden Republik Indonesia. }\end{array}$ \\
\hline Prospektif & $\begin{array}{l}\text { Dengan segala kekurangannya, Jakob Oetama menggaris bawahi bahwa sudah } \\
\text { sepatutnya Soeharto (kelak) dihormati dengan cara sepantasnya dan tetap dihargai } \\
\text { kebaikan dan keberhasilannya (27/1/2016). Dia tidak secara tegas menyebut tentang } \\
\text { layak tidaknya Soeharto diberi gelar Pahlawan Nasional sebagaimana yang pernah } \\
\text { atau masih diwacanakan oleh sejumlah pihak (termasuk Partai Golkar). }\end{array}$ \\
\hline
\end{tabular}

Sumber: Data Primer (2017)

Delapan tahun sebelumnya, terdapat tiga berita yang secara khusus memuat memori prospektif, memori tentang apa yang harus dilakukan bangsa Indonesia saat mengenang Soeharto. Pertama, berita bertajut "Pemimpin Bangsa Harus Belajar dari Kesalahan Soeharto" (27/1/2008). Memang tidak secara rinci menyebutkan kesalahan apa saja yang sebaiknya tidak boleh diulangi oleh pemimpin bangsa, tetapi secara langsung berita ini memberi instruksi tentang cara bersikap di masa yang akan datang.

Demikian pula halnya dengan berita kedua, "Pemberantasan KKN Jangan Dikubur Bersama Soeharto" (28/1/2008) yang menggarisbawahi korupsi, kolusi, dan nepotisme sebagai musuh bersama pasca-Soeharto. Meski dalam praktiknya, kita sebagai bangsa hanya fokus pada pemberantasan korupsi, dan tidak memberi porsi perhatian yang sama kepada praktik kolusi dan nepotisme.

Ketiga, berita berjudul "Belajar dari Pembangunan Pertanian Soeharto" (31/1/2008). Berita ini mengingatkan kisah sukses Soeharto dengan visi Rencana Pembangunan Lima Tahun (Repelita) yang berkesinambungan dan menjadikan sektor pertanian model awal kemandirian bangsa dengan swasembada pangannya. Tiga memori prospektif yang pernah mengemuka di tahun 2008 tersebut, tenggelam oleh wacana gelar Pahlawan Nasional yang ingin diberikan kepada Soeharto. 


\section{KESIMPULAN}

Framing memori dalam peringatan sewindu wafatnya Soeharto, lebih banyak yang menekankan pada aspek informatif dengan menyisakan catatan-catatan tentang sisi terang dan kelam Soeharto selama memerintah. Terjadi reduksi memori media di Kompas.com pada tahun 2016 —saat sewindu wafatnya Soeharto diperingati, jika dibandingkan dengan tahun 2008 ketika dia wafat. Ini dapat dimaknai sebagai bentuk penyederhanaan memori. Seiring waktu yang berlalu, setiap generasi membutuhkan satu simpul memori yang oleh media dianggap dapat merepresentasikan keseluruhan memori yang ada. Karakter media massa yang lebih fokus pada isu-isu aktual berkonsekuensi pada terbatasnya ruang untuk masa lalu. Kalau pun ada, ruang tersebut terbatas untuk episode-episode yang menonjol dan memiliki nilai berita dari sejarah, tidak menyajikan sejarah itu secara utuh.

Penelitian ini juga menunjukkan bahwa jurnalis sebagai agen memori, masih lebih menekankan peran retrospektifnya untuk merekonstruksi kembali apa yang telah terjadi. Ini bukan hasil yang mengejutkan, karena kecenderunga terebut sudah diisyaratkan Tenenboim-Weinblatt (2011: 214). Dalam konteks sewindu wafatnya
Soeharto di Kompas.com, tokoh dan peristiwa di masa lalu masih ditampilkan sebagai 'cermin' untuk melihat apa yang telah terjadi. Peran media sebagai agen memori prospektif untuk menemukan model masyarakat yang ingin dicapai (model for society), belumlah menonjol. Padahal rekomendasi dari masa lalu secara fungsional dapat digunakan untuk bertindak lebih arif di masa depan.

\section{DAFTAR PUSTAKA}

Adam, Asvi Warman. 2009. Pelurusan Sejarah Indonesia. Yogyakarta: Penerbit Ombak.

Aditjondro, George Junus. 2006. Korupsi Kepresidenan, Reproduksi Oligarki Berkaki Tiga: Istana, Tangsi, dan Partai Penguasa. Yogyakarta: LKiS.

Alexa. 2016. "Top Sites in Indonesia." April 5. http://www.alexa.com/topsites/c ountries/ID.

Eriyanto. 2011. Analisis Framing: Konstruksi, Ideologi, dan Politik Meida. Yogyakarta: LKiS.

Fine, Gary Alan. 2005. "Collective Memory." In Encyclopedia of Social Theory, edited by George Ritzer, 116-17. California: Sage Publications.

Goffman, Erving. 1974. Frame Analysis: An Essayon the Organization of Experience. New York: Harper \& Row.

Klinken, Gerry van. 2005. "The Battle for History After Suharto." In Beginning to Remember: The Past in the Indonesia Present, edited by Mary S. Zurbuchen, 233-60. Singapore: Singapore University Press.

McGlynn, John H., ed. 2007. Indonesia in the Soeharto Years: Issues, 
Incidents, and Images. 2nd ed. Jakarta: Lontar.

Pan, Zhongdang, and Gerald M. Kosicki. 1993. "Framing Analysis: An Approach to News Discourse." Political Communication 10 (1): 55-75.

Simpson, John H. 2011. "Afterword: What Is History?" In History, Time, Meaning, and Memory: Ideas for the Sociology of Religion, edited by Barbara Jones Denison, 255-64. Leiden: Koninklijke Brill NV.

Tenenboim-Weinblatt, Keren. 2011. "Journalism as an Agent of Prospective Memory." In On Media Memory: Collective Memory in A New Media Age, edited by Motti Neiger, Oren Meyers, and Eyal Zandber, 21325. London: Palgrave Macmillan. 